\title{
Relationship of Pleural Effusions to Increased Permeability Pulmonary Edema in Anesthetized Sheep
}

\author{
J. P. Wiener-Kronish, V. C. Broaddus, K. H. Albertine, M. A. Gropper, M. A. Matthay, and N. C. Staub \\ With the technical assistance of $\mathbf{O}$. Osorio \\ Cardiovascular Research Institute and Departments of Anesthesia, Medicine, and Physiology, University of California, San Francisco, \\ California 94143-0130; and Department of Medicine, Jefferson Medical College, Philadelphia, Pennsylvania 19107
}

\begin{abstract}
We studied anesthetized sheep to determine the relationship between increased permeability pulmonary edema and the development and mechanism of pleural effusion formation. In 12 sheep with intact, closed thoraces, we studied the time course of pleural liquid formation after $0.12 \mathrm{ml} / \mathrm{kg}$ i.v. oleic acid. After $1 \mathrm{~h}$, there were no pleural effusions, even though extravascular lung water increased $50 \%$ to $6.0 \pm 0.7 \mathrm{~g} / \mathrm{g}$ dry lung. By $3 \mathrm{~h}$ pleural effusions had formed, they reached a maximum at 5 $h(48.5 \pm 16.9 \mathrm{ml} /$ thorax $)$, and at $8 \mathrm{~h}$ there was no additional accumulation of pleural liquid $(45.5 \pm 16.9 \mathrm{ml})$. Morphologic studies by light and electron microscopy demonstrated subpleural edema but no detectable injury to the visceral pleura, suggesting that the pleural liquid originated from the lung and not the pleura. In nine sheep, we quantified the rate of formation of pleural liquid by enclosing one lung in a plastic bag. By comparing in the same sheep the volume of pleural liquid collected from the enclosed lung to the volume found in the opposite intact chest, we estimated the rate of liquid absorption from the intact chest to be $0.32 \mathrm{ml} /(\mathrm{kg} \cdot \mathrm{h})$; we had previously reported a liquid absorption rate of $0.28 \mathrm{ml} /(\mathrm{kg} \cdot \mathrm{h})$ in normal sheep. These studies also supported the conclusion that the majority of the pleural liquid originated from the lung because we could account for all of the pleural liquid that was formed and cleared. The volume of pleural liquid collected from the enclosed lungs was equal to $21 \%$ of the excess lung liquid that formed after oleic acid-induced lung injury. Thus, the pleural space and parietal pleural lymphatic pathways are important pathways for the clearance of pulmonary edema liquid after experimentally induced increased permeability pulmonary edema.
\end{abstract}

\section{Introduction}

In 1972, Cunningham and Hurley (1) noted the presence of pleural effusions in rats that had been given alpha-naphthylthiourea to produce an increased permeability pulmonary

Dr. Albertine's current address is Department of Medicine, Division of Pulmonary and Critical Care Medicine, Jefferson Medical College, Thomas Jefferson University, 1020 Locust Street, Philadelphia, PA 19107.

Address correspondence to Dr. J. P. Wiener-Kronish, Box 0130, CVRI, University of California, San Francisco, CA 94143-0130.

Received for publication 17 March 1988 and in revised form 24 May 1988.

J. Clin. Invest.

(C) The American Society for Clinical Investigation, Inc.

$0021-9738 / 88 / 10 / 1422 / 08 \quad \$ 2.00$

Volume 82, October 1988, 1422-1429 edema. A recent radiographic study at our institution documented the presence of pleural effusions in $36 \%$ of the patients with increased permeability pulmonary edema (2). We and other investigators have also found pleural effusions in patients who have increased permeability edema $(3,4)$. Nonetheless, very little is known about the pathophysiology of these pleural effusions.

To determine the relationship between increased permeability pulmonary edema and pleural effusions, we have used oleic acid to produce acute lung injury in two sets of experiments in anesthetized sheep. Initially, we used physiologic and morphologic techniques to study the time course, quantity, and origin of the pleural liquid in intact, closed-chested sheep. Then, in a second set of experiments, we opened one chest and adapted a technique from Kinasewitz et al. (5) to enclose the lung in a bag and collect all the liquid leaving one lung. With this method, we were able to directly measure liquid leaving the lung across the visceral pleura. Since this technique removes the parietal pleura which is the pathway for pleural liquid absorption (6), we were then able to calculate the absorption rate of pleural liquid from the intact chest by comparing the volume of pleural liquid formed in the open chest to the volume remaining in the opposite, closed chest in each animal. Since the volume of pleural fluid that formed was substantial, we also calculated the fractional contribution of the pleural space to the clearance of pulmonary edema in this experimental model.

\section{Methods}

Surgical preparation. We anesthetized 21 female or wethered yearling sheep $(32.6 \pm 6.2 \mathrm{~kg})$ with intravenous sodium pentothal $(30 \mathrm{mg} / \mathrm{kg})$, intubated the sheep with a cuffed endotracheal tube, and ventilated them with a constant volume pump (Harvard Apparatus Co., Inc., S. Natick, MA). The lungs were ventilated with a tidal volume of 12-15 $\mathrm{ml} / \mathrm{kg}$ and at a rate to maintain the $\mathrm{PaCO}_{2}$ between 30 and $40 \mathrm{mmHg}$. The $\mathrm{FlO}_{2}$ was adjusted to maintain a minimum $\mathrm{PaO}_{2}$ of $100 \mathrm{mmHg}$ even after edema developed. Positive end-expiratory pressure of $5 \mathrm{~cm}$ $\mathrm{H}_{2} \mathrm{O}$ was applied. Anesthesia was maintained postinduction with $1 \%$ halothane and the sheep were paralyzed with $1 \mathrm{mg}$ i.v. pancuronium bromide every $2 \mathrm{~h}$.

We placed a catheter into the carotid artery and floated a $7 \mathrm{~F}$ thermodilution catheter into the pulmonary artery (Edwards Laboratory, Santa Ana, CA). Another polyvinyl catheter (with PE50 tubing inserted inside it for the oleic acid infusion) was placed in the right atrium via the jugular vein. The sheep were placed prone on a warming blanket, and all transducers (Pd23ID; Gould, Inc., Oxnard, CA) were zeroed to the midchest level. Thermodilution cardiac outputs were determined using a dedicated on-line computer (model 3500; Mansfield Scientific, Mansfield, MA).

\section{Experimental protocol}

Closed-chest animals. We studied 12 sheep with both chests closed. During a 1-h baseline, pulmonary arterial, pulmonary arterial wedge, 
systemic arterial, and airway pressures as well as cardiac outputs were recorded every $15 \mathrm{~min}$. A hematocrit and arterial blood gas tensions were measured and plasma samples for protein concentration were obtained every $30 \mathrm{~min}$. Then, over $1 \mathrm{~h}$, oleic acid $(0.12 \mathrm{ml} / \mathrm{kg})$ (Sigma Chemical Co., St. Louis, MO) was infused through the PE50 catheter into the right atrium. Sheep were killed by exsanguination at different time periods after the beginning of the oleic acid infusion; two sheep at $1 \mathrm{~h}$, four sheep at $3 \mathrm{~h}$, three sheep at $5 \mathrm{~h}$, and three sheep at $8 \mathrm{~h}$. The sheep were then turned supine and underwent a median-sternotomy. We aspirated all the pleural liquid in each thorax using an infant feeding tube (Accumark feeding catheter, Concord Laboratories, Keene, NH). The lungs were removed and clamped at an airway pressure of $20 \mathrm{~cm} \mathrm{H}_{2} \mathrm{O}$, and alveolar edema liquid was aspirated from the distal air spaces using an infant feeding tube inserted into the distal bronchi. Specimens were taken for histology from the right upper and right lower lobes. The remainder of the lungs was then frozen in liquid nitrogen.

Unilateral open-chest animals. We then studied nine sheep with one chest open and one chest closed. The sheep were prepared in a fashion similar to the closed-chest animals. However, a left $(n=4)$ or right $(n=5)$ thoracotomy was done and the fifth to ninth ribs were removed en bloc 4 in. from the sternum to the spine. The exposed lung was enclosed in an impermeable clear polyethylene bag (Dow Chemical Co., Indianapolis, IN) that contained dried lithium heparin (5). The entire lung was enclosed; this was confirmed at the end of the experiment by inspection. A catheter was placed at the bottom of the bag to collect the pleural liquid. The sheep were turned prone and hemodynamic pressures and cardiac outputs were monitored every $15 \mathrm{~min}$ for a 2-h baseline period. Every half hour, pleural liquid was collected and plasma samples were obtained. There were five control sheep that were observed for a total of $6 \mathrm{~h}$. In the four other sheep, oleic acid $(0.12$ $\mathrm{ml} / \mathrm{kg}$ ) was infused into the right atrium and the sheep were monitored for $4 \mathrm{~h}$. The lungs were then removed as already described.

\section{Measurements of hemodynamics and protein concentration}

We measured systemic arterial, pulmonary arterial, pulmonary arterial wedge, and airway pressures at 15 -min intervals. We also measured cardiac outputs and arterial blood gases, as previously described (6). We measured total protein concentration of all liquids using an automated analyzer (AAII, Technicon Instruments Corp., Tarrytown, NY). Albumin concentration was determined by the bromcresol green binding method. Each lung was homogenized and the extravascular lung water and residual lung blood volume were determined by our standard technique (7).

\section{Histology}

Samples of lung tissue, including the overlying visceral pleura, were taken from three sheep in each experimental group. The tissue samples were $\sim 4 \mathrm{~cm}$ long and $2 \mathrm{~cm}$ wide and were taken from the free margin of the cranial and caudal lobes of the right lung by a double clamping procedure. Fixation was accomplished by flushing the visceral pleural surface with $2 \%$ glutaraldehyde/1\% paraformaldehyde in Millonig's phosphate buffer (320 mosM, pH 7.4) after the samples had been excised by cutting between the two clamps, and rinsing it with heparinized saline. Care was taken not to touch the visceral pleura. The same fixative was also injected into the lung tissue at several locations via a 25-gauge needle (0.1-0.2 ml per injection site) (8). The tissue samples were then immersed in fresh fixative for $24 \mathrm{~h}$.

Blocks of tissue for light microscopy $(0.75 \times 0.5 \times 0.2 \mathrm{~cm})$ were dehydrated through a graded ethanol series and embedded in glycol methacrylate, whereas tissue for electron microscopy $(1 \times 2 \times 4 \mathrm{~mm})$ was dehydrated through an acetone series and embedded in Polybed 812. The histologic sections ( $2 \mu \mathrm{m}$ thick) were stained with $1 \%$ toluidine Blue. Thick sections (60-80 nm thick) for ultrastructural evaluation were counterstained with uranyl acetate and lead citrate (9). A Zeiss Axioplan light microscope was used for histological observations and a Zeiss EM 9 was used for the ultrastructural studies.

\section{Statistics}

All data are presented as mean \pm SD. A one-way analysis of variance with a Neuman-Keuls multiple range test for multiple comparisons was used among the closed-chest sheep experiments. A paired $t$ test with Bonferroni's correction for multiple comparisons was used to compare hemodynamic data in the baseline period with the final intervals within each of the closed-chest experiments. A paired $t$ test was also used to test for differences in the same animal in the open-chest experiments. An unpaired $t$ test was used to test for differences between the rates of pleural liquid clearance in the closed-chest experiments compared with our prior data for pleural liquid clearance in normal sheep (10). We accepted $P<0.05$ as indicating statistically significant differences (11).

\section{Results}

Closed-chest experiments. Oleic acid induced several significant hemodynamic changes (Table I). The pulmonary arterial pressure was significantly increased at all time periods until 8 $\mathrm{h}$, after the baseline period. The pulmonary arterial wedge

Table I. Closed-chest Animals: Pleural Fluid Collected Compared with Hemodynamics and Extravascular Lung Water

\begin{tabular}{|c|c|c|c|c|c|}
\hline Time & $\begin{array}{l}\text { Pulmonary arterial } \\
\text { pressure* }\end{array}$ & $\begin{array}{l}\text { Pulmonary arterial } \\
\text { wedge pressure }\end{array}$ & Cardiac output & EVLW & Pleural fluid volume \\
\hline & $\mathrm{Cm} \mathrm{H}_{2} \mathrm{O}$ & $\mathrm{Cm} \mathrm{H}_{2} \mathrm{O}$ & liters/min & $g$ water/g dry lung & ml/thorax \\
\hline Control $(n=12)$ & $23 \pm 5$ & $13 \pm 3$ & $4.4 \pm 1.2$ & $\begin{array}{r}3.6 \pm 0.25 \\
(n=23)\end{array}$ & $\begin{array}{l}1.8 \pm 1.5^{\ddagger} \\
(n=23)\end{array}$ \\
\hline \multicolumn{6}{|l|}{ Oleic acid } \\
\hline $1 \mathrm{~h}(n=12)$ & $37 \pm 14^{\S}$ & $16 \pm 7^{\S}$ & $1.9 \pm 0.1^{8}$ & $\begin{array}{r}6.0 \pm 0.7 \\
(n=2)\end{array}$ & $\begin{array}{l}2.1 \pm 0.8 \\
(n=2)\end{array}$ \\
\hline $3 \mathrm{~h}(n=10)$ & $26 \pm 12^{8}$ & $11 \pm 5$ & $2.8 \pm 1.4^{\S}$ & $\begin{array}{r}6.5 \pm 0.7 \\
(n=4)\end{array}$ & $\begin{array}{c}13.6 \pm 8.7 \\
(n=4)\end{array}$ \\
\hline $5 \mathrm{~h}(n=6)$ & $47 \pm 22^{\S}$ & $14 \pm 1$ & $2.9 \pm 0.8$ & $\begin{array}{c}8.0 \pm 0.4^{\| \prime} \\
(n=3)\end{array}$ & $\begin{array}{c}48.5 \pm 16.9^{\prime \prime} \\
(n=3)\end{array}$ \\
\hline $8 \mathrm{~h}(n=3)$ & $38 \pm 8$ & $14 \pm 3$ & $3.7 \pm 0.4$ & $\begin{array}{r}6.6 \pm 0.6 \\
(n=3)\end{array}$ & $\begin{array}{c}45.5 \pm 16.9^{\| \prime} \\
(n=3)\end{array}$ \\
\hline
\end{tabular}

* All data are expressed as the mean \pm SD. ${ }^{\ddagger} 23$ normal sheep with closed chests used for controls for EVLW and pleural fluid volumes. ${ }^{\S}$ Significantly different by paired $t$ test for any experimental interval compared with its own baseline. "Significantly different by analysis of variance from other experimental periods. 
pressure was slightly elevated at $1 \mathrm{~h}$, but was not significantly different from control values at later time periods. Cardiac output fell significantly but returned to baseline by $8 \mathrm{~h}$ after the start of the infusion. At the end of the 1-h oleic acid infusion, alveolar edema was present and the extravascular lung water had nearly doubled. Commensurate with the development of alveolar edema, injury to the alveolar barrier was noted (Fig. 1). The epithelium became grossly swollen and distorted, whereas less severe but similar changes occurred in the endothelial cells of the alveolar capillaries.

The extravascular lung water from the 5-h experimental group was significantly higher than the lung water of animals studied at other time intervals. Alveolar edema could be suctioned from the endotracheal tube at all times after oleic acid.

Despite the fact that alveolar edema was present by the 1-h period, the pleural liquid volume obtained at $1 \mathrm{~h}$ was not significantly different from baseline (Table I). However, the pleural liquid volume significantly increased to 25 times over baseline levels in the 5- and 8-h experiments. The pleural liquid volumes in the 5- and 8-h experiments were significantly different from the volumes obtained in the prior intervals, but not different from each other (Fig. 2).

The pleural liquid protein concentration increased in the 3-h experiments and remained elevated above baseline in the 5- and 8-h experiments (Table II). The protein concentration of alveolar edema obtained at similar intervals was always higher than the protein concentration of the pleural liquid (Table II).

The final protein concentration of the edema fluid in the 8-h experiments showed a substantial increase above plasma
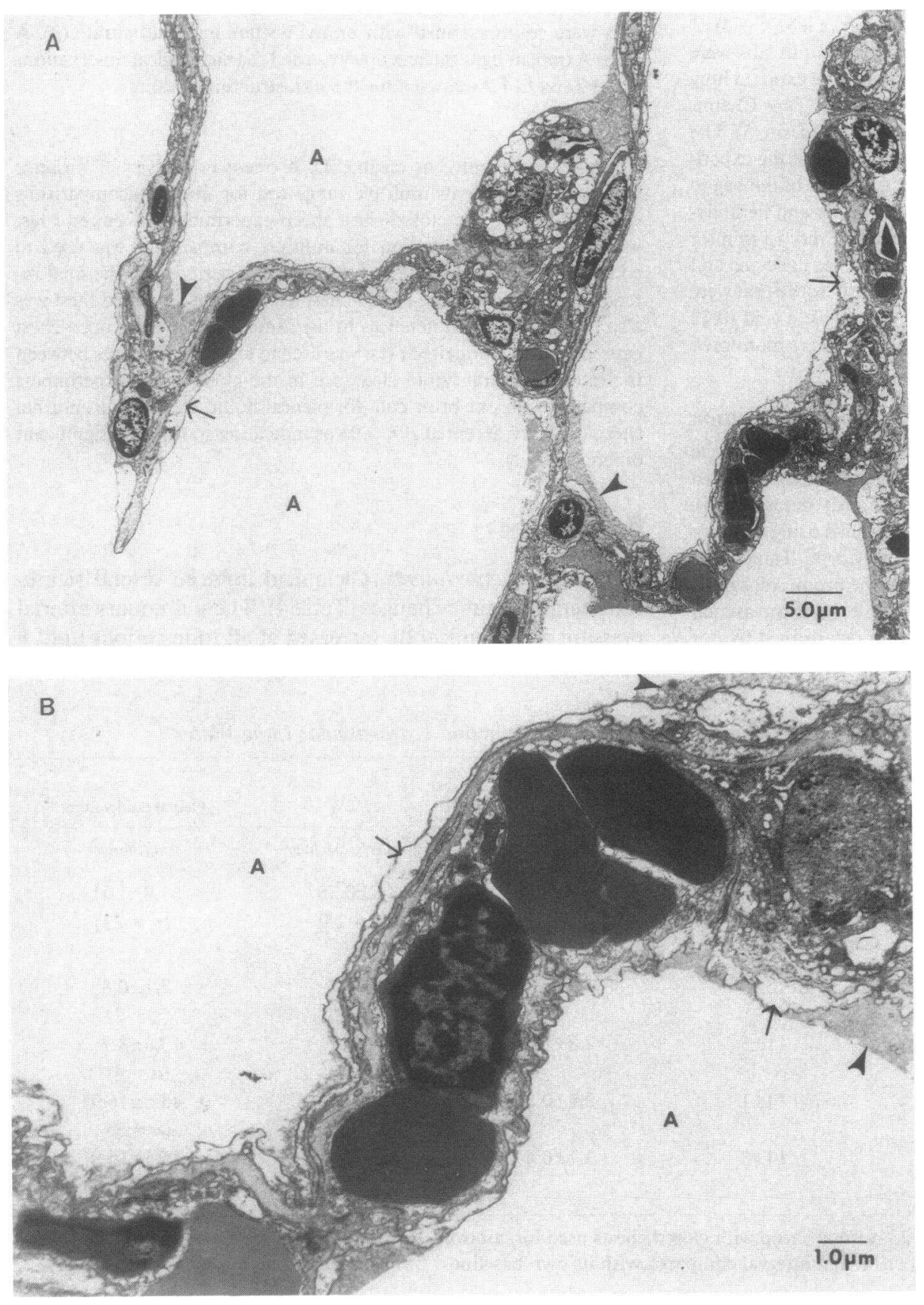

Figure 1. Electron micrographs illustrating alveolar $(A)$ epithelial cell damage at $1 \mathrm{~h}$ of oleic acid infusion. The cytoplasm of type I cells became swollen, distorted, and electron-lucent (arrows). Proteinaceous edema liquid (arrowheads) is present along the alveolar surface. $B$ shows the same figure at higher magnification. 


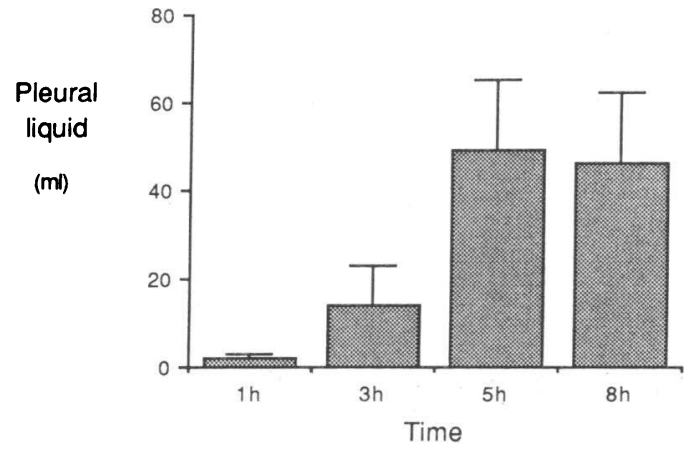

Figure 2. Pleural liquid volume (milliliters per thorax) in the closedchest experiments. The volumes obtained at the end of the 1-and 3-h experiments are not statistically different from each other or from baseline, but are different from the volumes obtained at 5 and $8 \mathrm{~h}$.

protein concentration, indicating that clearance of alveolar liquid was occurring (12).

Macroscopically, the first evidence of edema accumulation at the visceral pleural surface was distention of the interlobular septae, giving the surface of the lung a honeycomb appearance (Fig. 3). Histology of the visceral pleura showed progressive development of subpleural edema that was greatest in the 5and 8-h experiments (Fig. 4). The visceral pleural lymphatics became more prominent with time as well (Fig. 4). There was no evidence of injury to the visceral pleural mesothelial cells by light (Fig. 4) or ultrastructural (Fig. 5) examination.

Unilateral open-chest experiments. In the five control sheep that did not receive oleic acid, one lung was enclosed in a polyethylene bag for $6 \mathrm{~h}$, and $5.5 \pm 1.8 \mathrm{ml} / \mathrm{h}$ of pleural liquid formed. The volume of liquid collected was stable over the $6 \mathrm{~h}$. The total protein concentration of this liquid was $4.9 \pm 1.2 \mathrm{~g} / \mathrm{dl}$, significantly higher than the total protein concentration $(1.0 \pm 0.5 \mathrm{~g} / \mathrm{dl})$ for pleural liquid from normal sheep (6). The enclosed lung had a normal extravascular lung water, $3.9 \pm 0.4$ $\mathrm{g} / \mathrm{g}$ dry lung, compared with our prior controls of $3.6 \pm 0.3$ and with $3.8 \pm 0.3$, in the opposite, control lung.

In the four sheep who received oleic acid with one lung enclosed in a bag and the other chest closed, hemodynamics were similar to the closed-chest experiments. $2 \mathrm{~h}$ after beginning the oleic acid infusion, the pleural liquid formation rate increased significantly and remained elevated (Table III). The

Table II. Comparison of Total Protein Concentration Ratios in Pleural Liquid and Alveolar Edema Liquid in Closed-Chest Sheep

\begin{tabular}{ccc}
\hline \multicolumn{1}{c}{ Time } & $\begin{array}{c}\text { Protein concentration } \\
\text { (pleural liquid/plasma) }\end{array}$ & $\begin{array}{c}\text { Protein concentration } \\
\text { (alveolar liquid/plasma) }\end{array}$ \\
\hline Control $^{\ddagger}(n=23)$ & $0.2 \pm 0.1^{*}$ & - \\
Oleic acid & & 1.0 \\
$1 \mathrm{~h}(n=2)$ & $0.2 \pm 0.2$ & $1.1 \pm 0.1$ \\
$3 \mathrm{~h}(n=4)$ & $0.6 \pm 0.1^{\S}$ & $1.0 \pm 0.3$ \\
$5 \mathrm{~h}(n=3)$ & $0.6 \pm 0.1^{\S}$ & $1.3 \pm 0.1$ \\
$8 \mathrm{~h}(n=3)$ & $0.7 \pm 0.1^{\S}$ & \\
\hline
\end{tabular}

* Data are expressed as the mean \pm SD.

* Based on 23 normal sheep (6).

$\$$ Significantly elevated over baseline by analysis of variance. excess volume of pleural liquid obtained from the enclosed lungs was $71 \pm 48 \mathrm{ml}$ (total minus the baseline), which exceeded the volume from the contralateral, intact pleural space $(27 \pm 24$ $\mathrm{ml}$ ) (Table IV). The pleural liquid volume collected from the closed chest in these 4-h experiments was midway between the volume of liquid found in the pleural space at 3 and $5 \mathrm{~h}$ in the closed-chest experiments (Table I).

The protein concentration of the pleural liquid collected from the bag-enclosed lung was higher than that of the pleural liquid from the opposite, intact chest (Table IV). The pleural liquid-to-plasma protein concentration ratio increased from $0.7 \pm 0.0$ at baseline to $0.8 \pm 0.1$ after the oleic acid infusion (Table III). The protein concentration ratio then remained constant (Table III).

The mean extravascular lung water content of the enclosed lungs $(5.9 \pm 0.3 \mathrm{~g} / \mathrm{g}$ dry lung) was the same as that of the contralateral lungs in the opposite, intact chest $(5.8 \pm 0.2)$. The values from these 4-h experiments are similar to the extravascular lung waters measured for the sheep in the 3-h closed-chest experiments (Table I).

\section{Discussion}

The first objective of this study was to quantify the volume of pleural liquid that forms in the presence of experimentally induced acute lung injury. The second objective was to determine the time course and origin of the pleural effusions. The third objective was to segregate, if possible, the rates of formation and clearance of pleural liquid after oleic acid-induced lung injury. The final objective was to relate the volume of pleural liquid formed quantitatively to the increase in extravascular lung water.

The data in the closed-chest experiments demonstrate that moderate-sized pleural effusions are clearly associated with increased permeability pulmonary edema due to oleic acid lung injury in sheep (Fig. 2). The pleural effusions were first detectable at $3 \mathrm{~h}$, although pulmonary edema was present by $1 \mathrm{~h}$ with a wet/dry of $6.0 \pm 0.7 \mathrm{~g} / \mathrm{g}$ dry lung (Table I). The maximum quantity of pleural liquid collected was between 5 and $8 \mathrm{~h}$.

Pleural liquid did not dramatically increase right after the oleic acid infusion. This might seem surprising since gross alveolar flooding was present by $1 \mathrm{~h}$ and the extravascular lung water was increased to $6.0 \mathrm{~g}$ water/g dry lung. However, the 2-h lag may be explained by the time required for subpleural interstitial edema to collect and raise pressure sufficiently to generate liquid flow. In the morphologic studies, we found that subpleural edema was minimal at $1 \mathrm{~h}$ but prominent by $3 \mathrm{~h}$ (Fig. 4). Alveolar flooding may occur earlier because oleic acid has been shown recently to cause both an endothelial and epithelial injury (13). With an intact epithelial barrier, edema may accumulate in the interstitium, raising pressure, and effusions might occur more rapidly $(13,14)$. In separate experiments, we have studied the time course of pleural effusion formation in volume-overload pulmonary edema in sheep and found that the effusions do begin to accumulate within the first $1 \mathrm{~h}$ after the development of interstitial edema (15).

The pleural liquid collected in our experiments is similar to lung interstitial liquid formed after oleic acid-induced lung injury. In normal sheep, the total protein concentration of pleural liquid is low $(0.9-1.0 \mathrm{~g} / \mathrm{dl})$ and the pleural/plasma total 


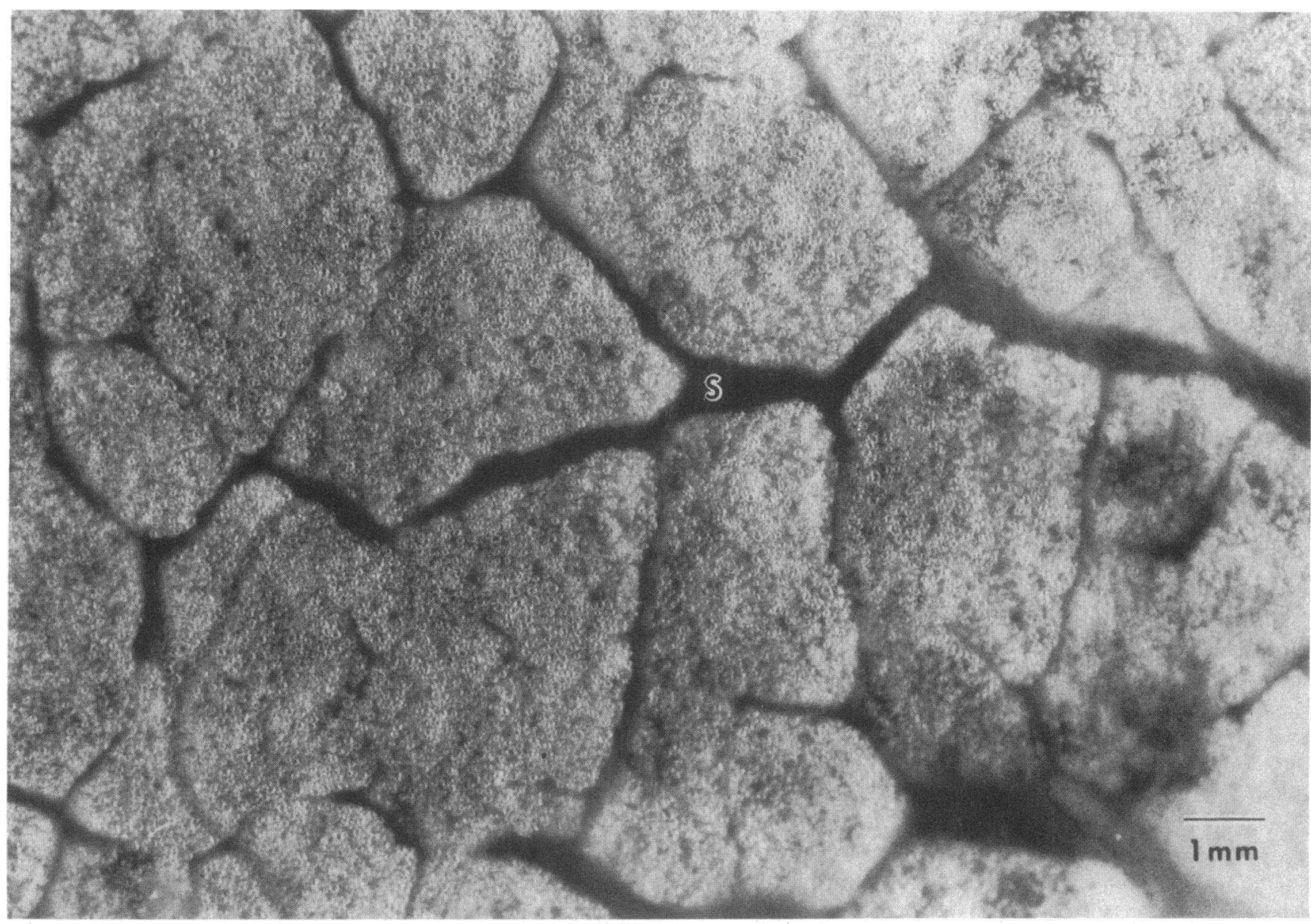

Figure 3. Macroscopic view of the lung's surface from a sheep given oleic acid for $1 \mathrm{~h}$. The interlobular septae $(S)$ are partially distended with edema liquid.

protein concentration ratio is $0.2 \pm 0.1$ (16). In our experiments, the total protein concentration of the pleural effusions varied from a normal ratio of 0.2 to a ratio of between 0.6 and 0.7 (Table II), suggesting a different source of the pleural liquid in the presence of pulmonary edema or a change in the permeability of the pleural microcirculation. In chronic, unanesthetized sheep given a comparable dose of oleic acid, the lymph/ plasma protein ratio was 0.72 (17), which is similar to our data for pleural liquid/plasma protein ratio in the closed-chest studies (Table II). This similarity between the pulmonary lymph protein and the pleural liquid protein suggests that the pleural effusions originate from interstitial lung edema that traverses the visceral pleura into the pleural space.

There was no evidence for increased permeability of the pleural microcirculations in the closed-chest experiments. Indeed, the delay in the development of the pleural liquid suggests that the immediate injury that occurred at the pulmonary microvascular endothelium and alveolar epithelium does not occur at the pleural surface. Our histologic studies also support this conclusion since no injury of the visceral pleura was identified. In fact, Pine and colleagues (18) noted sparing of the visceral pleura in acute lung injury in dogs. There is no reason for liquid to be added to the pleural space from the parietal or visceral circulations, since the plasma protein concentration did not change significantly, and the central venous and pulmonary arterial wedge pressures did not increase to levels that cause hydrostatic edema. Therefore, we conclude that the majority of the pleural liquid was formed from lung interstitial liquid. However, to directly determine the rate of pleural liquid formation and clearance, we adapted the technique of Kinasewitz (5) in the open-chest experiments.

In the open-chest experiments, we excluded the parietal pleura as a possible contributor of pleural liquid. Because the lateral chest wall was removed, the visceral pleura and lung were the only possible sources of the collected liquid, and absorption of the pleural liquid could not take place. The pleural liquid that formed was then compared with the net volume collected in the intact opposite chest in each animal, where absorption was occurring (Table IV).

The bag itself did cause some mild, stable pleural injury. In the five control experiments the pleural liquid formation rate was $5.5 \pm 1.8 \mathrm{ml} / \mathrm{h}$, and the liquid had a higher protein concentration $(4.9 \pm 1.2 \mathrm{~g} / \mathrm{dl})$ than found in normal sheep pleural liquid. However, over $6 \mathrm{~h}$, the rate of pleural liquid formation remained constant. Thus, we could subtract the baseline pleural accumulation rate from the rate seen after oleic acid. In these experiments, $26 \mathrm{ml}$ could be accounted for by the bag's effect on basal pleural liquid formation; $71 \mathrm{ml}$ more was collected after oleic acid was administered (Table IV). In the opposite, intact chest only $27 \mathrm{ml}$ was collected. Therefore, $44 \mathrm{ml}$ appears to have been absorbed over the 4-h interval, giving an absorption rate of $0.32 \mathrm{ml} /(\mathrm{kg} \cdot \mathrm{h})$. 

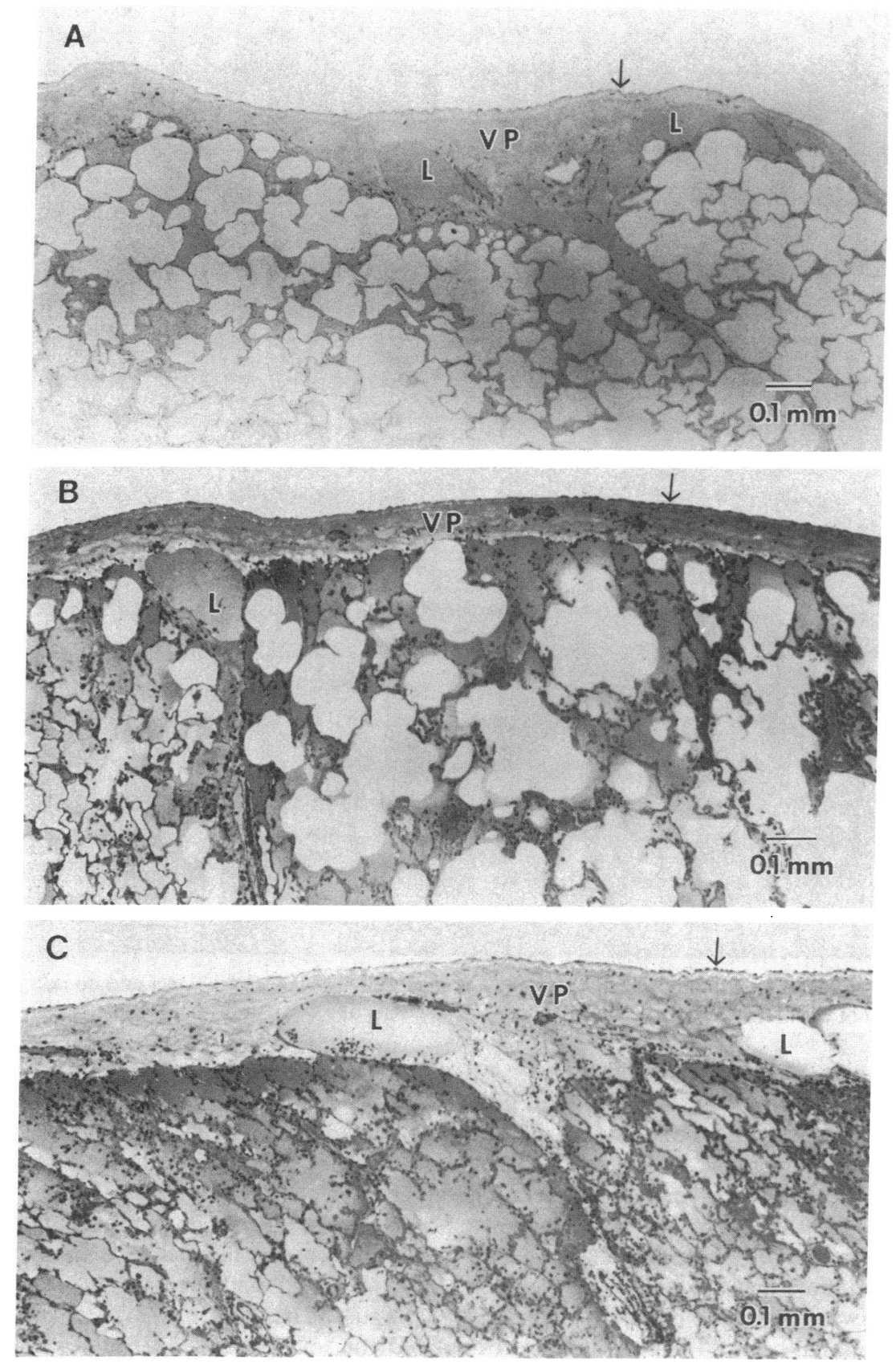

Figure 4. Histologic views of the sheep's lung and visceral pleura $1 \mathrm{~h}$ after oleic acid infusion $(A), 3$ $\mathrm{h}$ after oleic acid infusion $(B)$, and $8 \mathrm{~h}$ after oleic acid infusion $(C)$. Alveolar edema and infiltration of leukocytes were the first signs of acute lung injury. The visceral pleura $(V P)$ gradually became washed out and swollen due to tracking of the edema liquid along the interlobular septae. Lymphatics $(L)$ in the visceral pleura also became distended. Mesothelial cells (arrows) on the visceral pleural surface remained intact at all experimental time points that were studied.
We could, however, exclude the pleural liquid flow into the pleural space over the first hour after the infusion of oleic acid, since in both the open and closed experiments pleural liquid volume does not increase dramatically until the end of the second hour (Tables I and III). Calculating a reabsorption rate based on only the last $3 \mathrm{~h}$ of pleural liquid formation in the open-chest experiments, a volume of $64.7 \mathrm{ml}$ was formed (Table III). Since $37.7 \mathrm{ml}$ was reabsorbed over the 3-h interval $(64.7-27 \mathrm{ml}$ [Table IV]) the reabsorption rate when pleural liquid is actively being formed is $0.36 \mathrm{ml} /(\mathrm{kg} \cdot \mathrm{h})$. This new rate of pleural liquid absorption is not substantially different from the absorption rates we have reported $(0.28 \mathrm{ml} / \mathrm{kg} \cdot \mathrm{h})$ when we studied the clearance of sterile artifical hydrothoraces in unanesthetized sheep $(6,10)$. We conclude that pleural liquid absorption is probably normal after oleic acid-induced lung injury. Since we can account for all the liquid in the closed chest by the formation from the lung minus the absorption at the chest wall, this also suggests that there is no other major source of pleural liquid.

Comparison of the data in Tables I and III suggests that the time course of pleural liquid formation might be different in the closed-versus the open-chest sheep. There are two possible explanations for this apparent difference. First, the extravascular lung water $(E V L W)^{1}$ peaked at $5 \mathrm{~h}$ in the closed-chest sheep (8.0 $\pm 0.4 \mathrm{~g}$ water/g dry lung) (Table I), whereas the EVLW was $5.9 \pm 0.3$ at $4 \mathrm{~h}$ in the open-chest sheep (Table III). Thus, heterogeneity among the responses to oleic acid with a higher

1. Abbreviation used in this paper: EVLW, extravascular lung water. 


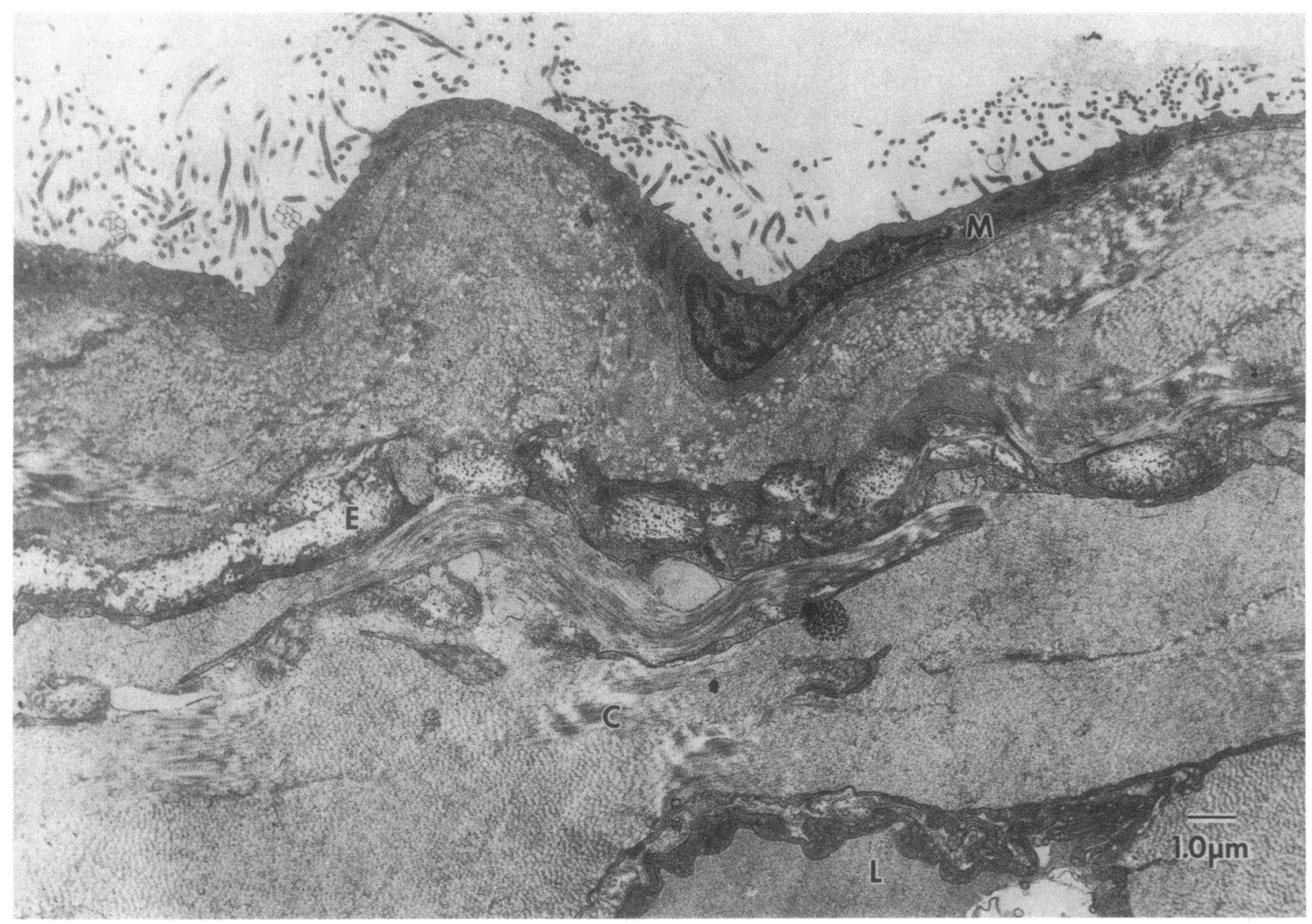

Figure 5. Ultrastructural appearance of the sheep's visceral pleura at $1 \mathrm{~h}$ of oleic acid infusion. The mesothelial cells $(M)$ are intact and do not show signs of injury. Beneath the mesothelium is a band of elastin $(E)$ and broad fields of collagen $(C)$. Part of a lymphatic $(L)$ is visible.

EVLW and thus a greater pleural liquid formation rate in the closed-chest sheep may explain the apparent higher pleural fluid formation rate in the closed- compared with the openchest sheep. However, the higher pleural liquid volume at 5 and $8 \mathrm{~h}$ in the closed-chest sheep experiments might also reflect reabsorption of alveolar edema that was transported into the interstitial space. In support of this explanation, note that the alveolar edema protein concentration rises between 5 and $8 \mathrm{~h}$ (Table II). Active reabsorption of alveolar liquid has been

Table III. Pleural Liquid Formation Rate in Four Sheep with One Lung Enclosed in a Bag

\begin{tabular}{cccc}
\hline Time & $\begin{array}{c}\text { Pleural } \\
\text { liquid flow }\end{array}$ & EVLW & Protein concentraton \\
\hline & $m l / h$ & $g$ water/g dry lung & pleural liquid/plasma \\
Baseline & $6.6 \pm 4.8^{*}$ & - & $0.7 \pm 0$ \\
OA $^{\ddagger}$ infusion & $10.7 \pm 4.3$ & - & $0.8 \pm 0.1$ \\
$2 \mathrm{~h}$ & $31.6 \pm 14.5$ & - & $0.8 \pm 0.1$ \\
$3 \mathrm{~h}$ & $31.7 \pm 26.9$ & - & $0.8 \pm 0.1$ \\
$4 \mathrm{~h}$ & $21.2 \pm 15.3$ & $5.9 \pm 0.3$ & $0.8 \pm 0$ \\
\hline
\end{tabular}

$*$ Mean \pm SD.

‡OA, oleic acid. shown to occur in sheep and to cause alveolar protein concentration (12). The reabsorption of alveolar edema would increase the EVLW in the interstitial space and possibly cause an increase in pleural liquid accumulation.

The open-chest experiments also allowed us to estimate the percentage of excess EVLW that entered the pleural space. By adding the volume of pleural liquid obtained in the openchest, bag-enclosed lung (minus the baseline flow) to the excess lung water, we calculated the total volume of pulmonary edema present in these experiments. This was done by taking the $Q w l / d Q L$ of each lung and subtracting our normal value of 3.6. This result was then multiplied by the $d Q L$, the excess dry weight found in each lung water determination (12). This

Table IV. Pleural Liquid and Protein in Four Sheep: Bag Compared with Intact Chest

\begin{tabular}{lcc}
\hline & $\begin{array}{c}\text { Pleural liquid } \\
\text { in bag }\end{array}$ & $\begin{array}{c}\text { Pleural liquid } \\
\text { in intact chest }\end{array}$ \\
\hline Excess volume $(m l)$ & $71 \pm 48^{\ddagger *}$ & $27 \pm 24^{\S}$ \\
Total protein concentration $(g / d l)$ & $4.4 \pm 0.6$ & $3.4 \pm 0.7^{\S}$
\end{tabular}

* Mean \pm SD.

* Total volume minus the baseline formation rate $\times 4 \mathrm{~h}$.

${ }^{\S}$ Significantly different by paired $t$ test (bag vs. intact chest). 
product $(111 \mathrm{ml} \pm 52)$ was added to the pleural liquid volume $(71 \pm 48)$ for a volume of $182 \mathrm{ml}$. The reported excess lung lymph flow after $0.12 \mathrm{ml} / \mathrm{kg}$ of intravenous oleic acid is $41 \pm 19$ $\mathrm{ml} / \mathrm{h}$ (or $164 \mathrm{ml}$ ) for $4 \mathrm{~h}$ after an oleic-acid infusion (17). We added all of this lymph volume even though it reflects flow from both lungs because lung lymph flow in sheep probably collects only about one-half of the lymph from each lung. The total volume of excess lung water accumulation (pleural liquid, excess water in the lungs, and the excess lung lymph flow) calculates to $346 \mathrm{ml}$. The pleural liquid volume $(71 \mathrm{ml})$ then accounts for $21 \%$ of the total excess liquid formed after oleicacid lung injury. Thus, the pleural leak represents a new significant pathway for clearance of lung edema.

In conclusion, pleural effusions develop in sheep after increased permeability pulmonary edema is produced by oleic acid. The effusions are of moderate size and have a total protein concentration similar to lung lymph, suggesting that the pleural liquid originates from the pulmonary interstitium primarily. This is different from normal pleural liquid, which is believed to be formed by the parietal and visceral pleural microcirculations. Since $\sim 21 \%$ of the extravascular lung water accumulated as pleural fluid, the pleural space is an important pathway for removal of edema from the lung.

\section{Acknowledgments}

The authors wish to thank Bernie Baccay for her assistance in preparing this manuscript.

Dr. Wiener-Kronish was supported in part by National Institutes of Health (NIH) grants HL101033 (Clinical Investigator Award) and HL19155 (Pulmonary Vascular SCOR). Dr. Broaddus was supported in part by NIH grants HL01893 (Clinical Investigator Award) and HL19155 (Pulmonary Vascular SCOR). Dr. Matthay was supported in part by NIH Program Project grant HL25816. Dr. Albertine was supported in part by NIH grant $\mathrm{H} 138075$.

\section{References}

1. Cunningham, A. L., and J. V. Hurley. 1972. Alpha-naphthylthiourea-induced pulmonary oedema in the rat: a topographical and electron-microscope study. J. Pathol. 106:25-35.

2. Aberle, D. R., J. P. Wiener-Kronish, W. R. Webb, and M. A. Matthay. 1988. The diagnosis of hydrostatic versus increased permeability edema based on chest radiographic criteria in critically ill patients. Radiology. 168:73-79.
3. Miller, K. S., C. Wittschen-Brown, and S. A. Sahn. 1987. Pleural effusions in ethchlorvynol induced adult respiratory distress syndrome from lung leak. Am. Rev. Respir. Dis. 135:A191. (Abstr.)

4. Wiener-Kronish, J. P., R. Goldstein, and M. A. Matthay. 1988. Pleural effusions are frequently associated with the adult respiratory distress syndrome. Am. Rev. Respir. Dis. 137:A227. (Abstr.)

5. Kinasewitz, G. T., and A. P. Fishman. 1981. Influence of alterations in Starling forces of visceral pleural fluid movement. J. Appl. Physiol. 51:671-677.

6. Wiener-Kronish, J. P., K. H. Albertine, V. Licko, and N. C. Staub. 1984. Pleural fluid protein clearance rates in anesthetized and unanesthetized sheep. J. Appl. Physiol. 56:459-463.

7. Selinger, S. L., R. D. Bland, R. H. Demling, and N. C. Staub. 1975. Distribution volume of ${ }^{131} \mathrm{I}$-albumin, ${ }^{14} \mathrm{C}$-sucrose and ${ }^{36} \mathrm{Cl}$ in sheep lung. J. Appl. Physiol. 39:773-779.

8. Bachofen, M., E. R. Weibel, and B. Roos. 1977. Post mortem fixation of human lungs for electron microscopy. Am. Rev. Respir. Dis. 116:589-615.

9. Albertine, K. H., J. P. Wiener-Kronish, K. Koike, and N. C. Staub. 1984. Quantification of damage by air emboli to lung microvessels in anesthetized sheep. J. Appl. Physiol. 57:1360-1368.

10. Broaddus, V. C., J. P. Wiener-Kronish, Y. Berthiaume, and N. C. Staub. 1988. Removal of pleural liquid and protein by lymphatics in awake sheep. J. Appl. Physiol. 64:384-390.

11. Zar, J. H. 1984. Biostatistical Analysis. Prentice Hall, Inc., Englewood Cliffs, NJ. 620 pp.

12. Berthiaume, Y., N. C. Staub, and M. A. Matthay. 1987. Betaadrenergic agonists increase lung liquid clearance in anesthetized sheep. J. Clin. Invest. 79:335-343.

13. Montaner, J. S. B., J. Tsang, K. G. Evans, J. B. M. Mullen, A. R. Burns, D. C. Walker, B. Wiggs, and J. C. Hogg. 1986. Alveolar epithelial damage: a critical difference between high pressure and oleic acid induced low pressure pulmonary edema. J. Clin. Invest. 77:1786-1796.

14. Staub, N. C. 1974. Pathogenesis of pulmonary edema. Am. Rev. Respir. Dis. 109:358-372.

15. Broaddus, V. C., J. P. Wiener-Kronish, E. H. Jerome, N. Matsumoto, K. Miyamoto, and N. C. Staub. 1986. Pleural effusions in volume overload pulmonary edema. Physiologist. 29:104. (Abstr.)

16. Staub, N. C., J. P. Wiener-Kronish, and K. H. Albertine. 1985. Transport through the pleura: physiology of normal liquid and solute exchange in the pleural space. In The Pleura in Health and Disease. J. Chretien, J. Bignon, and A. Hirsch, editors. Marcel Dekker Inc., New York. 169-189.

17. Julien, M., J. M. Hoeffel, and M. R. Flick. 1986. Oleic acid injury in sheep. J. Appl. Physiol. 60:433-440.

18. Pine, M. B., M. Beach, T. S. Cottrell, M. Scola, and G. M. Turino. 1976. The relationship between right duct lymph flow and extravascular lung water in dogs given alpha-naphthyl-thiourea. $J$. Clin. Invest. 58:482-492. 